\title{
Reliable Identification of Bacillus cereus Group Species Using Low Mass Biomarkers by MALDI-TOF MS
}

\author{
Miyoung $\mathrm{Ha}^{1 *}$, Hyeon-Ju Jo ${ }^{1}$, Eun-Kyeong Choi ${ }^{2}$, Yangsun $\mathrm{Kim}^{2}{ }^{2}$, Junsung $\mathrm{Kim}^{1}$, and Hyeon-Jong Cho ${ }^{1}$ \\ ${ }^{1}$ Nonghyup Food Research Institute, Suwon 16506, Republic of Korea \\ ${ }^{2}$ ASTA Inc. AICT, Suwon 16229, Republic of Korea
}

Received: March 15, 2019

Revised: May 29, 2019

Accepted: June 3, 2019

First published online

June 7, 2019

*Corresponding author

Phone: +82-31-8021-7052

Fax: +82-31-8021-7018;

E-mail: hamisukwon@hanmail.net

pISSN 1017-7825, eISSN 1738-8872

Copyright(C) 2019 by

The Korean Society for Microbiology and Biotechnology

\begin{abstract}
Matrix-assisted laser desorption/ionization time-of-flight mass spectrometry (MALDI-TOF MS)-based pathogen identification relies on the ribosomal protein spectra provided in the proprietary database. Although these mass spectra can discern various pathogens at species level, the spectra-based method still has limitations in identifying closely-related microbial species. In this study, to overcome the limits of the current MALDI-TOF MS identification method using ribosomal protein spectra, we applied MALDI-TOF MS of low-mass profiling to the identification of two genetically related Bacillus species, the food-borne pathogen Bacillus cereus, and the insect pathogen Bacillus thuringiensis. The mass spectra of small molecules from 17 type strains of two bacilli were compared to the morphological, biochemical, and genetic identification methods of pathogens. The specific mass peaks in the low-mass range $(\mathrm{m} / \mathrm{z} 500$ $3,000)$ successfully identified various closely-related strains belonging to these two reference species. The intensity profiles of the MALDI-TOF mass spectra clearly revealed the differences between the two genetically-related species at strain level. We suggest that small molecules with low molecular weight, 714.2 and $906.5 \mathrm{~m} / \mathrm{z}$ can be potential mass biomarkers used for reliable identification of $B$. cereus and B. thuringiensis.
\end{abstract}

Keywords: MALDI-TOF MS, food-borne pathogen, discrimination, Bacillus cereus, Bacillus thuringiensis

\section{Introduction}

Matrix-assisted laser desorption and ionization time-offlight mass spectrometry (MALDI-TOF MS) has emerged as a new technology for species identification [1-7]. The MALDI-TOF MS-based identification method can be used to analyze the protein profiles of intact bacterial cells. The method is a rapid and powerful tool because of its speed, reproducibility, and sensitivity of analysis [8,9]. The speed and simplicity of sample preparation and result acquisition associated with minimal consumable cost make this method suitable for routine and high-throughput use for microorganism identification [1, 10-13]. The identification of the target microorganism using MALDI-TOF MS is based on the comparison of the protein mass spectra of the microorganism obtained from MALDI-TOF MS to the spectrum in a reference database. Bacterial MALDI spectra databases usually contain mass peaks of ribosomal proteins accounting for $>20 \%$ of the total cellular proteins $[14,15]$. However, one drawback in using the MALDI-TOF MSbased identification method is that some species do not have sufficient differences in their ribosomal protein sequences. For instance, Shigella spp. and Escherichia coli cannot be distinguished using MALDI-TOF MS [16]. Similarly, the members of the Bacillus spp., such as B. cereus, B. anthracis, B. thuringiensis, B. mycoides, B. megaterium, and $B$. subtilis, cannot be distinguished by proteins having less than $50 \mathrm{kDa}$ of molecular weight when microfluidic capillary electrophoresis is applied [17].

The Bacillus cereus group [18] of rod-shaped, Grampositive bacteria comprises six closely-related Bacillus species: B. cereus, B. anthracis, B. thuringiensis, B. mycoides, 
B. pseudomycoides, and B. weihenstephanensis [19, 20]. The $B$. cereus species is an important pathogen in humans and animals [21-24]. Of all the Bacillus spp., the most common pathogen in humans is B. cereus, an opportunistic pathogen involved in various illnesses such as food poisoning [25, 26]. Another pathogen is $B$. thuringiensis, which produces $\delta$ endotoxin crystals, commonly referred to as Bt toxin. This pathogen was used in biopesticides because of its lethality to insect larvae [27]. The B. cereus group species can be distinguished from other members of the aerobic endospore-forming bacteria because of its inability to produce acid from mannitol and lecithinase production [18]. Members of the B. cereus group exhibit different phenotypic characteristics used for their identification. For example, B. anthracis is non-motile, non-hemolytic, and non-penicillin resistant, which distinguishes it from $B$. cereus, B. thuringiensis, and B. mycoides [28]. Both B. cereus and $B$. thuringiensis are motile; however, $B$. thuringiensis can be distinguished from $B$. cereus based on its ability to produce the Bt toxin [29-31]. However, it is known that phenotypic tests and sequence analysis of the 16S rRNA genes could fail to differentiate between members of the B. cereus group [32]. Species-specific identification of $B$. cereus group species using polymerase chain reaction (PCR) is problematic because of the close homology between particular species of this group [33], for which reason some authors have suggested as genetically being the same species [30, 34].

Current laboratory methods used for the identification of the B. cereus group are mainly based on the morphological, physiological, and biochemical characteristics of the species. Conventional identification methods are time-consuming, taking up to $48 \mathrm{~h}[12,35,36]$ and are unreliable because of poor discrimination between closely-related species, such as B. cereus, B. thuringiensis, and B. mycoides. In addition, supplementary tests are often recommended for an accurate identification of species that are misidentified, i.e., in cases where the species identified is discordant with the reference information or are unidentified [37]. Therefore, rapid and reliable, closely-related Bacillus identification methods are required for food safety control by routine analysis.

In this study, we developed a pathogen identification method by seeking biomarker candidates to distinguish between $B$. cereus and $B$. thuringiensis while overcoming the limits of current MALDI-TOF MS-based identification techniques. We attempted to find biomarkers with differences in intensity profiles of specific low-mass peaks that vary by species using MALDI-TOF MS analysis.

\section{Materials and Methods}

\section{Bacterial Strains}

We analyzed 22 strains belonging to the B. cereus group and related species obtained from the Korean Collection for Type Culture (KCTC) (Table 1). Freeze-dried cultures in Pyrex ampules were resuspended in $0.5 \mathrm{ml}$ sterile water. A $100-\mu \mathrm{l}$ volume of each suspension was smeared onto mannitol-egg yolk-polymyxin (MYP, USA) agar plates and incubated at $30^{\circ} \mathrm{C}$ for $24 \mathrm{~h}$.

\section{Biochemical Analysis}

Biochemical identification of the bacterial strains was carried out using VITEK 2 Compact (bioMérieux SA, Marcy l'Etoile, France). A colony showing pink color on MYP agar was cultured on nutrient agar to make bacterial suspensions, which were prepared using $3 \mathrm{ml}$ of sterile saline and adjusted to a McFarland standard (2.0) using DensiChek (bioMérieux). The Bacillus identification card (BCL) (bioMérieux) was filled automatically in the VITEK vacuum chamber, sealed, and incubated at $35.5^{\circ} \mathrm{C}$, and read automatically every $15 \mathrm{~min}$ for $16 \mathrm{~h}$. Data were analyzed automatically using the VITEK2 database version 7.01. Identification results were reported as described previously [37]. Briefly, the species was reported as either (i) correctly identified to a single species or more than one species in a "slashline," in which case supplementary testing was required to distinguish between similar species; (ii) misidentified (where the species identified using BCL was discordant with the results of $16 \mathrm{~S}$ rRNA sequencing); or (iii) unidentified.

\section{PCR Amplification and Sequencing of 16S rRNA Genes}

Bacterial genomic DNA was extracted using a Labopass Tissue Mini Prep Kit (Cosmo Genetech Co. Ltd., Korea), according to the manufacturer's instructions. The $16 \mathrm{~S}$ rRNA sequences were PCR amplified with the primers 27F (5'-AGA GTT TGA TCM TGG CTC AG-3') and 1492R (5'-GGT TAC CTT GTT ACG ACT T-3') $[38,39]$ using the following conditions: initial denaturation at $94^{\circ} \mathrm{C}$ for $3 \mathrm{~min}$; followed by 35 cycles of denaturation at $94^{\circ} \mathrm{C}$ for $30 \mathrm{sec}$; annealing at $58^{\circ} \mathrm{C}$ for $30 \mathrm{sec}$; and extension at $72^{\circ} \mathrm{C}$ for $30 \mathrm{sec}$. PCR products were purified and sequenced at Macrogen, Korea, using the primers 785F (5'-GGATTAGATACCCTGGTA-3') and 907R (5'-CCGTCAATTCMTTTRAGTTT-3'). The resulting sequences, approximately $1.5 \mathrm{~kb}$ in size, were aligned and submitted for a similarity search in the National Center for Biotechnology Information (NCBI) database using the BLAST 2 Sequence [40]. Query sequences with $\geq 99 \%$ sequence similarity were used for the identification of the PCR-amplified 16S rRNA sequences. Partial $16 \mathrm{~S}$ rRNA sequences were compared with known sequences in the NCBI Genbank database. The sequences were as follows: B. cereus (NR114582.1, NR115526.1, NR074540.1, NR112630.1, NR113266.1, NR115714.1), B. thuringiensis (NR043403.1, NR114581.1), B. anthracis (NR041248.1), B. weihenstephanensis (NR024697.1), B. mycoides (NR115993.1, NR036880.1, NR113990.1), B. pseudomycoides (NR113991.1) 
Table 1. Assignment of Bacillus species using biochemical, transmission electron microscope analysis, and 16S rRNA gene sequencing.

\begin{tabular}{|c|c|c|c|c|c|c|}
\hline No. & & & $\begin{array}{c}\text { Biochemical } \\
\text { analysis }\end{array}$ & $\begin{array}{c}16 S \text { rRNA gene } \\
\text { sequencing }\end{array}$ & $\begin{array}{l}\text { Presence } \\
\text { of crystal }\end{array}$ & $\begin{array}{l}\text { Assignment } \\
\text { of species }\end{array}$ \\
\hline 1 & B. cereus & КСТС 1014 & B. cereus/B. thuringiensis/B. mycoides & B. thuringiensis & + & B. thuringiensis \\
\hline 2 & B. cereus & КСТС 1661 & B. cereus/B. thuringiensis/B. mycoides & B. thuringiensis & - & B. cereus \\
\hline 3 & B. cereus & КСТС 3624 & B. cereus/B. thuringiensis/B. mycoides & B. thuringiensis & - & B. cereus \\
\hline 4 & B. cereus & КСТС 3124 & B. cereus/B. thuringiensis/B. mycoides & B. thuringiensis & - & B. cereus \\
\hline 5 & B. cereus & KCTC 1013 & B. cereus/B. thuringiensis/B. mycoides & B. thuringiensis & - & B. cereus \\
\hline 6 & B. thuringiensis & КСТC 1508 & B. cereus/B. thuringiensis/B. mycoides & B. cereus & - & B.cereus \\
\hline 7 & B. thuringiensis & КСТС 3452 & B. cereus/B. thuringiensis/B. mycoides & B. thuringiensis & + & B. thuringiensis \\
\hline 8 & B. thuringiensis & КСТС 1524 & Brevibacillus laterosporis & B. cereus & - & B. cereus \\
\hline 9 & B. thuringiensis & КСТС 1525 & B. cereus/B. thuringiensis/B. mycoides & B. thuringiensis & - & B. cereus \\
\hline 10 & B. thuringiensis & КСТС 1511 & B. cereus/B. thuringiensis/B. mycoides & B. thuringiensis & + & B. thuringiensis \\
\hline 12 & B. mycoides & КСТC 3453 & Brevibacillus laterosporis & B. cereus & - & B. cereus \\
\hline 13 & B. megaterium & КСТС 3708 & Brevibacillus laterosporis & B. cereus & - & B. cereus \\
\hline 14 & B. megaterium & KCTC 1098 & B. cereus/B. thuringiensis/B. mycoides & B. cereus & - & B. cereus \\
\hline 15 & B. megaterium & KCTC 1316 & B. cereus/B. thuringiensis/B. mycoides & B. cereus & + & B. thuringiensis \\
\hline 16 & B. megaterium & КСТС 2194 & B. megaterium & B. megaterium & & B. megaterium \\
\hline 17 & B. megaterium & КСТС 3712 & B. smithii & B. megaterium & & B. megaterium \\
\hline 18 & B. megaterium & KCTC 1366 & Brevibacillus laterosporis & B. cereus & - & B. cereus \\
\hline 19 & B. megaterium & КСТС 2178 & B. megaterium & B. megaterium & & B. megaterium \\
\hline 20 & B. megaterium & КСТС 3007 & B. cereus/B. thuringiensis/B. mycoides & B. thuringiensis & - & B. cereus \\
\hline 21 & B. subtilis & KCTC 13241 & Unidentified & B. megaterium & & B. megaterium \\
\hline
\end{tabular}

\section{Observation of Parasporal Crystals Using Transmission Electron Microscope (TEM)}

Bacillus cereus group and related species were grown on MYP medium for 1 day at $30^{\circ} \mathrm{C}$. Bacterial cells were prepared for TEM analysis, as described previously [41]. Briefly, bacterial cells were resuspended in Karnovsky's fixative prepared in $0.1 \mathrm{M}$ sodium cacodylate buffer, $10 \%$ paraformaldehyde, and $8 \%$ glutaraldehyde and stored at $4^{\circ} \mathrm{C}$ overnight. Later, the pellets were washed three times with $0.05 \mathrm{M}$ sodium cacodylate buffer and post-fixed with $1 \%$ osmium tetroxide in $0.05 \mathrm{M}$ cacodylate buffer for $2 \mathrm{~h}$ at $4^{\circ} \mathrm{C}$. Subsequently, the samples were washed with cold distilled water twice and stained in $0.5 \%$ uranyl acetate overnight. Samples were then subjected to a serial dehydration process using three 10-min incubations in ethanol at 30\%,50\%,70\%,80\%, 90\%, and $100 \%$ each. The dehydrated cells were embedded in Spurr's resin mixture and cured at $70^{\circ} \mathrm{C}$ for $48 \mathrm{~h}$. Ultra-thin sections were prepared using an ultramicrotome (EM UC7, Germany). Samples were observed using the energy-filtering TEM (LIBRA 120 equipped with Olympus SIS-iTEM version 5.0 [build 1243], CarlZeiss, Germany).

\section{MALDI-TOF MS Analysis}

Bacterial colonies grown on culture medium were directly placed on the MALDI target plate as a thin layer and allowed to air dry. Two microliters of $70 \%$ formic acid (Merck, Germany) were applied to the sample layer [13, 42], allowed to dry, and overlaid with $2 \mu \mathrm{l}$ of matrix solution consisting of $10 \mathrm{mg} / \mathrm{ml}$ $\alpha$-cyano-4-hydroxy-cinnamic acid (Fluka, Switzerland) saturated in 2.5\% trifluoroacetic acid (Sigma-Aldrich, USA) and 50\% acetonitrile (Honeywell Burdick \& Jackson, Fisher Scientific). The matrix and analyte were allowed to co-crystalize, and the target plate was inserted into the MALDI-TOF MS instrument. Mass spectra were automatically acquired with MALDI-TOF MS operating in a linear positive mode by accumulating 1,000 laser shots in the $\mathrm{m} / \mathrm{z}$ ranges $2,000-20,000$ and 500-3,000 using Thinkerbell LT (ASTA Inc., Korea). External calibration of mass spectra was performed using recombinant E. coli extracts (ASTA Inc.,) in a protein mass range of 3,000-20,000 Da and Peptide Calibration Standard II (Bruker Daltonics, Germany) in a small molecule mass range of 500-3,000 Da. 


\section{Results and Discussion}

\section{Assignment of Reference Bacillus Species}

The use of reference strains with a well-defined taxonomic status is a prerequisite for reliable identification of unidentified strains [12]. Moreover, errors in conventional identification methods may lead to discordant results of MALDI-TOF MS identification [3]. Due to the high genetic and phenotypic similarity between $B$. thuringiensis and $B$. cereus [31, 43], they might represent the same species [30], thus could not be distinguished based on sequencing alone [44]. For these reasons, we paid special attention to the verification of 22 strains to ensure specific biomarkers for reliable identification of $B$. cereus and B. thuringiensis. Twenty-two strains of Bacillus species obtained from stock collection were investigated in this study, including B. cereus $(n=5), B$. thuringiensis $(n=6), B$. mycoides $(n=1)$, B. megaterium) $(n=8)$, and B. subtilis $(n=2)$ (Table 1$)$. We examined the strains based on biochemical identification, 16S rRNA gene sequencing, and parasporal crystal observation. As shown in Table 1, the strains belonging to five Bacillus species were identified into one of three Bacillus species: B. cereus; B. thuringiensis; and B. megaterium.

Biochemical analysis using BCL card identified 20 of the 22 strains but two strains of B. subtilis remained unidentified by the analysis. Of these identified 20 strains, 12 strains were matched with the strain ID information. However, eight strains showed ambiguous identification different from the original nomenclature. Biochemical identification of the bacterial strains was confirmed via PCR amplification and partial sequencing of the $16 \mathrm{~S}$ rRNA genes using the primer pairs $27 \mathrm{~F} / 1492 \mathrm{R}$ and $785 \mathrm{~F} / 907 \mathrm{R}$. The matched 12 strains with original nomenclature were also confirmed as B. cereus, B. thuringiensis or B. megaterium by $16 \mathrm{~S}$ rRNA gene sequencing. Two unidentified strains (KCTC 13241 and 3135) in the biochemical analysis were identified as B. megaterium by $16 \mathrm{~S}$ rRNA gene sequencing. Among the mismatched eight strains with strain ID information, three strains identified as B. cereus/B. thuringiensis/B. mycoides in the biochemical analysis were confirmed with similar results by $16 \mathrm{~S}$ rRNA gene sequencing but five strains were identified as a $B$. cereus or B. megaterium. To distinguish between $B$. cereus and $B$. thuringiensis, 17 strains identified as $B$. cereus or $B$. thuringiensis were observed for the presence or absence of cuboid or diamond-shaped parasporal crystals using TEM $[43,45]$. The parasporal crystals were observed only in 5 out of the 17 strains, and the KCTC 1014, $3452,1511,1507$, and 1316 strains were finally identified as B. thuringiensis (Fig. 1).

\section{Differentiation between $B$. cereus and $B$. thuringiensis Strains}

Protein mass patterns of B. cereus and B. thuringiensis were theoretically distinguished using an algorithm that applied the intensity factor to the relative intensity of protein mass peaks [13]. However, these two species could not be distinguished because both were in the highly reliable ranking when evaluating unused reference strains in the MALDI-TOF MS database [13]. This may not represent each species because of the high sequence diversity between $B$. cereus and B. thuringiensis strains [46]. Therefore, we compared the heat maps showing the relative peak intensities to determine if there are common protein markers that distinguish the two species when using several well-validated standard strains. MALDI-TOF MS spectra were derived from three Bacillus species, B. cereus $(n=12), B$. thuringiensis $(n=5)$, and B. megaterium $(n=5)$, grown on blood agar plates (BAP), MYP, and trypticase soy agar (TSA) media. Seventy peaks were extracted from the MALDI-TOF MS spectra and ordered according to the relative intensity for 22 strains of the three Bacillus species. $\mathrm{m} / \mathrm{z}$ Bins at 1,200 ppm intervals were made at 3,00020,000. Different colors indicated different peak intensities; red indicated high intensity, green indicated low intensity,
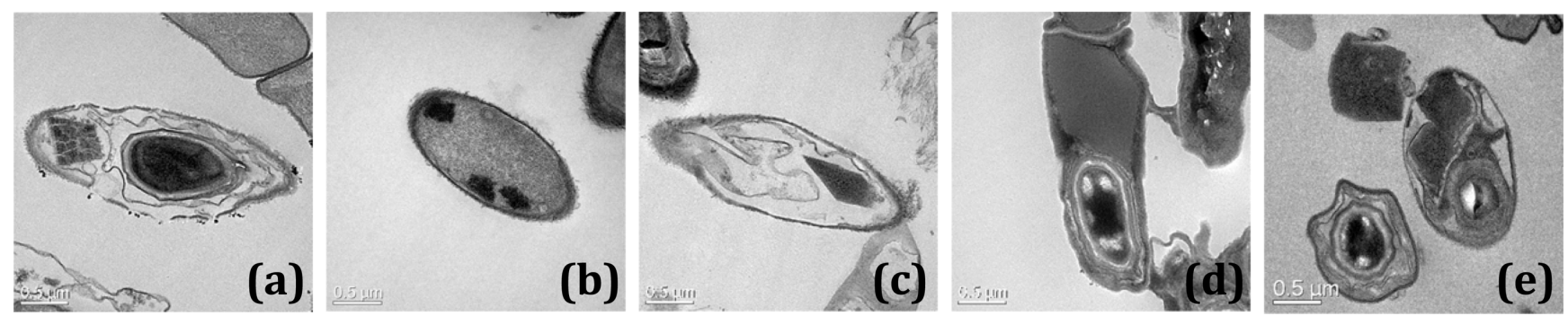

Fig. 1. Transmission electron microscopy images of parasporal crystals of (a) KCTC 1014, (b) KCTC 3452, (c) KCTC 1511, (d) KCTC 1507, and (e) KCTC 1316. 


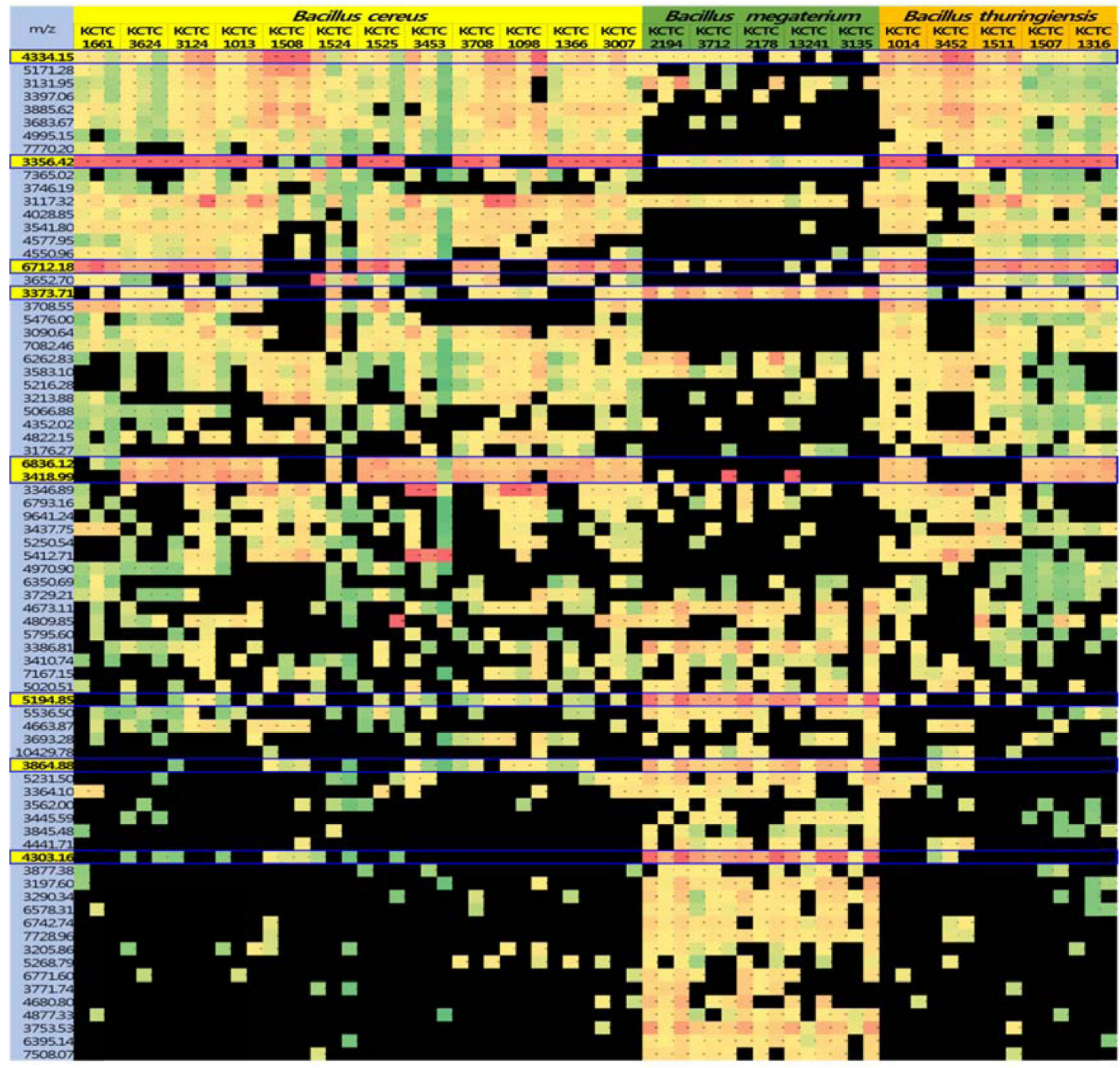

Fig. 2. Heat map of protein mass peaks derived from 22 bacterial strains assigned into three Bacillus species, $B$. cereus $(n=12)$, B. thuringiensis $(n=5)$, and B. megaterium $(n=5)$.

Red color indicates high peak intensity, green indicates low peak intensity, and black indicates absence of peak.

and black indicated absence of peaks. The heat map in Fig. 2 demonstrated a high degree of spectral reproducibility and indicated a relatively high degree of similarity between spectra from strains belonging to the same species members and, conversely, distinct spectra from strains belonging to different species. B. megaterium ( $n$ $=5)$ was characterized as having significantly different protein mass peaks, $\mathrm{m} / \mathrm{z}$ of $3373,3864,4303$, and 5194, compared with B. cereus $(n=12)$ and B. thuringiensis $(n=5)$. $B$. cereus and $B$. thuringiensis shared two dominant mass peaks: $\mathrm{m} / \mathrm{z} 3356$ (double-charged ion), and 6712. The specific peak at m/z 6712 was the spore marker protein of $B$. cereus and B. thuringiensis [47-49]. However, no protein mass peaks were found to allow for the reliable differentiation between the two species. MALDI-TOF protein mass spectra of the two species were not different even when the culture conditions were changed (data not shown). As previously reported, we reaffirmed that the discovery of species-specific protein markers using MALDI-TOF MS protein profiling was hampered by the high genetic similarity existing within $B$. cereus and $B$. thuringiensis.

Discovery of Species-Specific Biomarkers Using LowMass Profiling by MALDI-TOF

Wilson et al. reported that $B$. cereus excretes two catecholate 


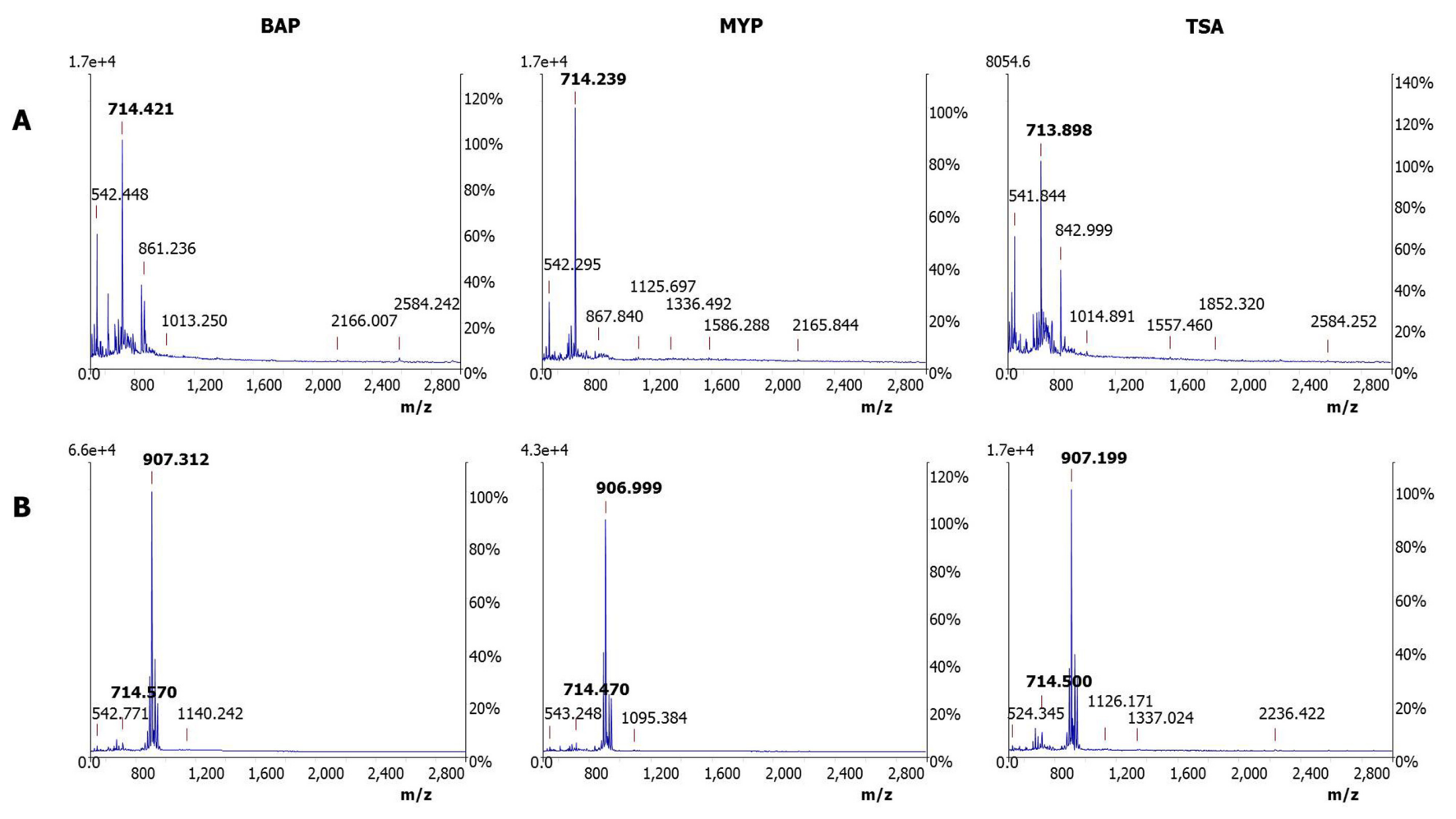

Fig. 3. MALDI-TOF MS spectra obtained from the representative strains of B. cereus (KCTC 3124) (A) and B.thuringiensis (KCTC1507) (B) in the low-mass range (500-3,000 m/z).

BAP: blood agar plates; MYP: mannitol-egg yolk-polymyxin agar; TSA: trypticase soy agar

siderophores, petrobactin $\left(\mathrm{m} / \mathrm{z} 719.3[\mathrm{M}+\mathrm{H}]^{+}\right.$, which contains 3,4-dihydroxybenzoyl moieties) and bacillibactin $\left(\mathrm{m} / \mathrm{z} 883.2[\mathrm{M}+\mathrm{H}]^{+}\right.$, which contains 2,3-dihydroxybenzoyl moieties), whereas $B$. thuringiensis produces only bacillibactin [50]. Therefore, we attempted to identify small molecules that could potentially distinguish between the strains of $B$. cereus and $B$. thuringiensis studied here using rapid and accurate MALDI-TOF MS. The MALDI-TOF MS spectra obtained from the representative strains of B. cereus (KCTC 3124) and B. thuringiensis (KCTC 1507) in the range of 500$3,000 \mathrm{~m} / \mathrm{z}$ are shown in Fig. 3. These strains were cultured on BAP, MYP, and TSA, respectively. The spectra of $B$. cereus and $B$. thuringiensis shared mass peaks at $\mathrm{m} / \mathrm{z}$ 714.2 and 906.5 ; however, the intensity of the peaks greatly differed between B. cereus and B. thuringiensis, regardless of the culture conditions. The dominant mass peaks were $714.2 \mathrm{~m} / \mathrm{z}$ for B. cereus and $906.5 \mathrm{~m} / \mathrm{z}$ for B. thuringiensis. The heat map in Fig. 4 shows the spectral- and speciesspecific reproducibility for differences of intensity profiles from 17 verified strains: B. cereus $(n=12)$ and B. thuringiensis $(n=5)$. At this time, the tolerance of mass peak was 500 ppm. The list of the peak of low molecules detected by MALDI-
TOF was shown in the light blue section of Fig. 4. Thirtynine mass peaks were listed that were detected more than $50 \%$ in each species, and the intensity profile for each peak was visually represented by a heat map. Ten $B$. cereus and three $B$. thuringiensis strains showed high peak intensities at $\mathrm{m} / \mathrm{z} 714$ and 906, respectively (Fig. 4). However, two B. cereus (KCTC 1611 and 3007) and two B. thuringiensis (KCTC 3452 and 1316) strains showed contradictory results. While KCTC 1661 and 3007 strains were classified as B. cereus strains because of the absence of parasporal crystals, the intensity profiles of these strains were similar to those of B. thuringiensis strains. B. thuringiensis harbors the $C r y$ genes that encode insecticidal crystal toxins, and B. thuringiensis strains that lack Cry genes are indistinguishable from $B$. cereus $[43,51]$. Thus, these strains may be $B$. thuringiensis strains that could not be distinguished from B. cereus because they lack the Cry genes and do not produce crystals. Indeed, KCTC 1661 and 3007 strains did not contain Cry1Ab/Ac and Cry2A, which are encoded by the abundant Cry 1 and Cry2 genes in most B. thuringinensis isolates [52] when tested using the ImmuneStrips (Agdia Incorporated, USA) (data not shown). KCTC 3452 and 


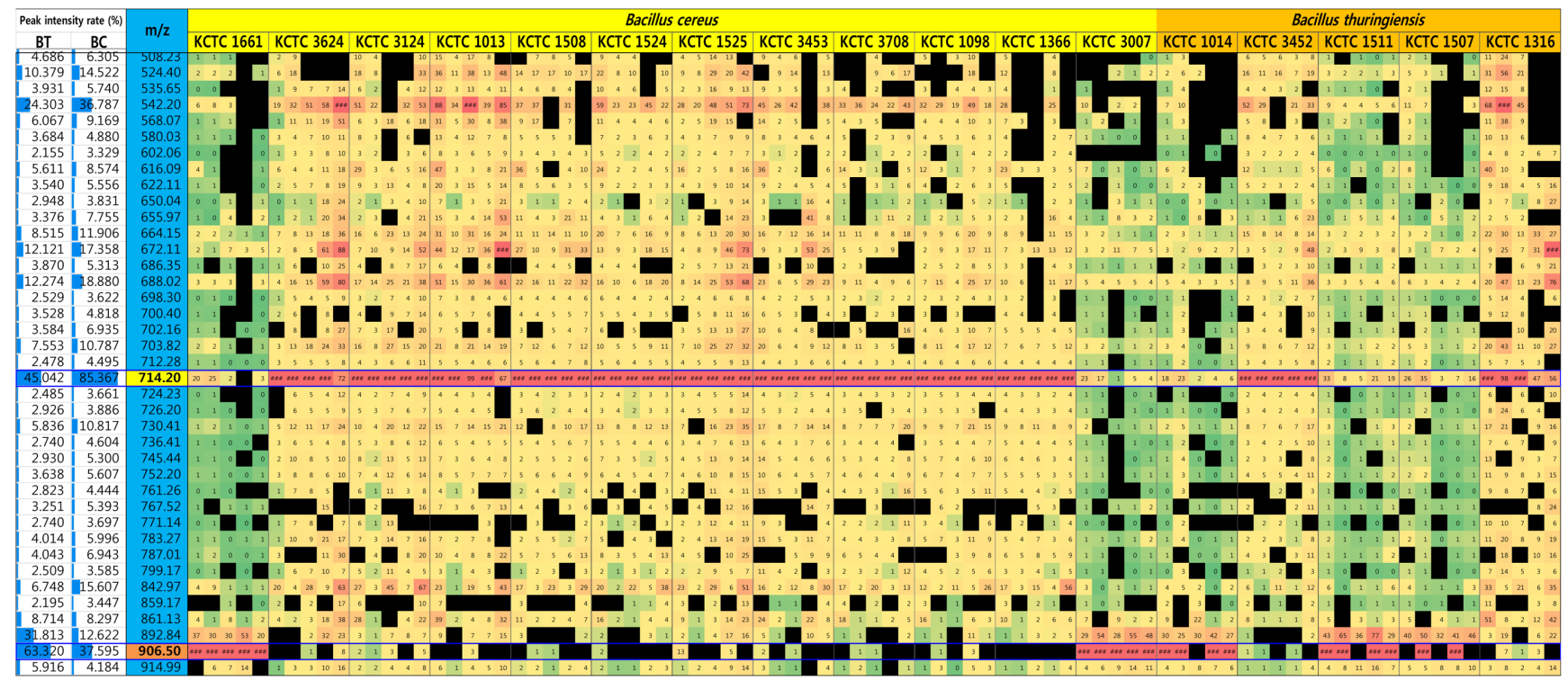

Fig. 4. Heat map of the small molecule mass peaks derived from B. cereus $(n=12)$ and B. thuringiensis $(n=5)$ in the low-mass range $(500-3,000 \mathrm{~m} / \mathrm{z})$.

KCTC 1316 were assigned to $B$. thuringiensis because of the presence of crystals. These two strains also had the Cry genes; Cry1Ab/Ac in KCTC 3452, and Cry1Ab/Ac and Cry $2 \mathrm{~A}$ in KCTC 1316 were detected by the ImmuneStrips (Agdia Incorporated, USA) (data not shown). However, the low-mass patterns of these strains were similar to those of B. cereus. Cry genes encoded by the plasmid show a high potential for horizontal gene transfer between $B$. thuringiensis and B. cereus $[25,53,54]$. It is possible that KCTC 3452 and KCTC 1316 underwent horizontal transfer of Cry genes, which made it difficult to distinguish between the two species, B. cereus and B. thuringiensis.

When the four strains were reclassified according to the low-mass patterns analyzed by MALDI-TOF, the intensity rate of two mass peaks, m/z 714.2 and 906.5, was significantly

Table 2. Peak intensity rates for two mass peaks, $\mathrm{m} / \mathrm{z} 714.2$ and 906.5.

\begin{tabular}{cccc}
\hline \multirow{2}{*}{ Species } & Mass & \multicolumn{2}{c}{ Reclassification criteria } \\
\cline { 3 - 4 } & $\begin{array}{c}\text { peak } \\
(\mathrm{m} / \mathrm{z})\end{array}$ & $\begin{array}{c}\text { Presence of } \\
\text { crystals by TEM }\end{array}$ & $\begin{array}{c}\text { Low-mass } \\
\text { patterns by MALDI }\end{array}$ \\
\hline B. cereus & 714.2 & 85.4 & 97.3 \\
$($ BC, $n=12)$ & 906.5 & 37.6 & 2.7 \\
B. thuringiensis & 714.2 & 45.0 & 13.5 \\
$(\mathrm{BT}, n=5)$ & 906.5 & 63.3 & 100.0 \\
\hline
\end{tabular}

TEM, transmission electron microscope; MALDI, matrix-assisted laser desorption/ionization. exchanged between the two species (Table 2). For B. cereus, the intensity rate of $\mathrm{m} / \mathrm{z} 714.2$ increased from 85.4 to 97.3 and that of $\mathrm{m} / \mathrm{z} 906.5$ decreased from 37.6 to 2.7 , whereas for $B$. thuringiensis, the intensity rate of $\mathrm{m} / \mathrm{z} 714.2$ decreased from 45.0 to 13.5 and that of $\mathrm{m} / \mathrm{z} 906.5$ increased from 63.3 to 100.0. These changes indicated that these two peaks have increased potential as biomarkers for the distinction of the two species. Also, low-mass patterns from MALDI-TOF MS could distinguish between $B$. cereus and B. thuringiensis, even if the morphological phenotype was misleading.

\section{Evaluation of Biomarker Candidates to Distinguish B. cereus} and $B$. thuringiensis

The biomarker candidates 714.2 and $906.5 \mathrm{~m} / \mathrm{z}$ were evaluated for reliable discrimination of the B. cereus and B. thuringiensis strains isolated from actual contaminated food. The twenty-six isolates were identified as twenty B. cereus and six B. thuringiensis by the presense of parasporal crystals. Of the 26 isolates, 23 strains were consistent with the results of identification by MALDI-TOF MS biomarkers. as shown in Table 3. Three strains (R33, R42, and R50) were identified as $B$. cereus because no crystals were identified, but the MALDI-TOF MS biomarkers were identified as $B$. thuringiensis. This may be the $B$. thuringiensis deficient in the Cry gene as described above, which could not be distinguished in the conventional method. Therefore, the MALDI-TOF MS biomarkers presented in this study showed that it is well applied to actual samples in distinguishing 
Table 3. Evaluation of the biomarker candidates, $\mathrm{m} / \mathrm{z} 714.2$ and 906.5 , to distinguish B. cereus and B. thuringiensis.

\begin{tabular}{|c|c|c|c|c|c|c|}
\hline \multirow{3}{*}{ No } & \multirow{3}{*}{$\begin{array}{l}\text { Isolated strains } \\
\text { from food }\end{array}$} & \multicolumn{2}{|c|}{ TEM } & \multicolumn{3}{|c|}{ MALDI-TOF } \\
\hline & & \multirow{2}{*}{ Presence of crystals } & \multirow{2}{*}{ Identification } & \multicolumn{2}{|c|}{ Relative peak intensity rates } & \multirow[t]{2}{*}{ Identification } \\
\hline & & & & $714.2 \pm 0.5$ & $906.5 \pm 0.5$ & \\
\hline 1 & R1 & - & B. cereus & 86 & 14 & B. cereus \\
\hline 2 & $\mathrm{R} 2$ & - & B. cereus & 100 & 0 & B. cereus \\
\hline 3 & R3 & - & B. cereus & 98 & 2 & B. cereus \\
\hline 4 & R23 & - & B. cereus & 100 & 0 & B. cereus \\
\hline 5 & R24 & - & B. cereus & 95 & 5 & B. cereus \\
\hline 6 & R33 & - & B. cereus & 23 & 77 & B. thuringiensis \\
\hline 7 & R34 & + & B. thuringiensis & 29 & 71 & B. thuringiensis \\
\hline 8 & R42 & - & B. cereus & 14 & 86 & B. thuringiensis \\
\hline 9 & R43 & + & B. thuringiensis & 30 & 70 & B. thuringiensis \\
\hline 10 & R44 & + & B. thuringiensis & 14 & 86 & B. thuringiensis \\
\hline 11 & R45 & + & B. thuringiensis & 18 & 82 & B. thuringiensis \\
\hline 12 & R46 & - & B. cereus & 90 & 11 & B. cereus \\
\hline 13 & R47 & + & B. thuringiensis & 0 & 100 & B. thuringiensis \\
\hline 14 & R48 & - & B. cereus & 92 & 8 & B. cereus \\
\hline 15 & R49 & + & B. thuringiensis & 0 & 100 & B. thuringiensis \\
\hline 16 & R50 & - & B. cereus & 0 & 100 & B. thuringiensis \\
\hline 17 & R256 & - & B. cereus & 91 & 9 & B. cereus \\
\hline 18 & $\mathrm{R} 257$ & - & B. cereus & 100 & 0 & B. cereus \\
\hline 19 & R258 & - & B. cereus & 100 & 0 & B. cereus \\
\hline 20 & R259 & - & B. cereus & 100 & 0 & B. cereus \\
\hline 21 & R260 & - & B. cereus & 100 & 0 & B. cereus \\
\hline 22 & R261 & - & B. cereus & 100 & 0 & B. cereus \\
\hline 23 & R262 & - & B. cereus & 100 & 0 & B. cereus \\
\hline 24 & R263 & - & B. cereus & 100 & 0 & B. cereus \\
\hline 25 & R264 & - & B. cereus & 100 & 0 & B. cereus \\
\hline 26 & R265 & - & B. cereus & 100 & 0 & B. cereus \\
\hline
\end{tabular}

B. cereus from B. thuringiensis. These findings will help in the development of efficient diagnostic tools based on the MALDI-TOF MS database for the rapid identification of biomarkers to differentiate between $B$. cereus and B. thuringiensis strains.

\section{Acknowledgments}

This research was supported the by Basic Science Research Program through the National Research Foundation of Korea funded by the Ministry of Science, ICT \& Future Planning (2015037599).

\section{Conflict of Interest}

The authors have no financial conflicts of interest to declare.

\section{References}

1. Barbuddhe SB, Maier T, Schwarz G, Kostrzewa M, Hof H, Domann E, et al. 2008. Rapid identification and typing of listeria species by matrix-assisted laser desorption ionizationtime of flight mass spectrometry. Appl. Environ. Microbiol. 74: 5402-5407.

2. Bessède E, Solecki O, Sifré E, Labadi L, Mégraud F. 2011. Identification of Campylobacter species and related organisms by matrix assisted laser desorption ionization-time of flight (MALDI-TOF) mass spectrometry. Clin. Microbiol. Infect. 17: 1735-1739.

3. Bizzini A, Durussel C, Bille J, Greub G, Prod'hom G. 2010. Performance of matrix-assisted laser desorption ionizationtime of flight mass spectrometry for identification of bacterial strains routinely isolated in a clinical microbiology laboratory. J. Clin. Microbiol. 48: 1549-1554. 
4. Dieckmann R, Strauch E, Alter T. 2010. Rapid identification and characterization of Vibrio species using whole-cell MALDI-TOF mass spectrometry. J. Appl. Microbiol. 109: 199211.

5. Grosse-Herrenthey A, Maier T, Gessler F, Schaumann R, Böhnel H, Kostrzewa M, et al. 2008. Challenging the problem of clostridial identification with matrix-assisted laser desorption and ionization-time-of-flight mass spectrometry (MALDI-TOF MS). Anaerobe 14: 242-249.

6. Sparbier K, Weller U, Boogen C, Kostrewa M. 2010. Rapid detection of Salmonella sp. by means of a combination of selective enrichment broth and MALDITOF MS. Eur. J. Clin. Microbiol. Infect. Dis. 31: 767-773.

7. Szabados F, Woloszyn J, Richter C, Kaase M, Gatermann S. 2010. Identification of molecularly defined Staphylococcus aureus strains using matrix-assisted laser desorption/ionization time of flight mass spectrometry and the Biotyper 2.0 database. J. Med. Microbiol. 59: 787-790.

8. Petersen CE, Valentine NB, Wahl KL. 2009. Characterization of microorganisms by MALDI mass spectrometry. Methods Mol. Biol. 492: 367-379.

9. Public Health England. 2015. UK standards for microbiology investigations (ID 9): Identification of Bacillus species, bacteriology-identification. 3: 1-27.

10. Croxatto A, Prod'hom G, Greub G. 2012. Application of MALDI-TOF mass spectrometry in clinical diagnostic microbiology. FEMS Microbiol. Rev. 36: 380-407.

11. Seibold E, Maier T, Kostrzewa M, Zeman E, Splettstoesser W. 2010. Identification of Francisella tularensis by whole-cell matrix-assisted laser desorption ionization-time of flight mass spectrometry: Fast, reliable, robust, and cost-effective differentiation on species and subspecies levels. J. Clin. Microbiol. 48: 1061-1069.

12. Seng P, Drancourt M, Gouriet F, La Scola B, Fournier PE, Rolain JM, et al. 2009. Ongoing revolution in bacteriology: Routine identification of bacteria by matrix-assisted laser desorption ionization time-of-flight mass spectrometry. Clin. Infect. Dis. 49: 543-551.

13. Ha M, Son EJ, Choi EJ. 2016. Application of MALDI-TOF mass spectrometry-based identification of foodborne pathogen tests to the Korea Food Standard Codex. Korean J. Food Sci. Technol. 48: 437-444.

14. Ryzhov V, Fenselau C. 2001. Characterization of the protein subset desorbed by MALDI from whole bacterial cells. Anal. Chem. 73: 746-750.

15. Bremer H, Dennis PP. 1996. Modulation of chemical composition and other parameters of the cell by growth rate. Cell. Mol. Biol., pp. 167-182. In Neidhardt FC (ed.), Escherichia coli and Salmonella. ASM Press, Washington, DC.

16. Wieser A, Schneider L, Jung J, Schubert S. 2012. MALDITOF MS in microbiological diagnostics-identification of microorganisms and beyond (mini review). Appl. Microbiol. Biotechnol. 93: 965-974.
17. McLaughlin J, Nelson M, McNevin D, Roffey P, Gahan ME. 2014. Characterization of Bacillus strains and hoax agents by protein profiling using automated microfluidic capillary electrophoresis. Forensic Sci. Med. Pathol. 10: 380-389.

18. Fritze D. 2004. Taxonomy of the genus bacillus and related genera: the aerobic endospore-forming bacteria. Phytopathology 94: $1245-1248$.

19. Ehling-Schulz M, Svensson B, Guinebretiere $M H$, Lindbäck $T$, Andersson M, Schulz A, et al. 2005. Emetic toxin formation of Bacillus cereus is restricted to a single evolutionary lineage of closely related strains. Microbiology 151(Pt. 1): 183-197.

20. Lindbäck T, Granum PE. 2006. Detection and purification of Bacillus cereus enterotoxins. In Adley, C. C., (Ed.), Foodborne Pathogens: Methods and Protocols, pp. 15-26. Humana Press, Totowa, NJ.

21. Gaviria Rivera AMG, Granum PE, Priest FG. 2000. Common occurrence of enterotoxin genes and enterotoxicity in Bacillus thuringiensis. FEMS Microbiol. Lett. 190: 151-155.

22. Stenfors LP, Mayr R, Scherer S, Granum PE. 2002. Pathogenic potential of fifty Bacillus weihenstephanensis strains. FEMS Microbiol. Lett. 215: 47-51.

23. Ehling-Schultz M, Fricker M and Scherer S. 2004. Bacillus cereus, the causative agent of an emetic type of food-borne illness. Mol. Nutr. Food Res. 48: 479-487.

24. Schoeni JL, Wong AC. 2005. Bacillus cereus food poisoning and its toxins. J. Food Prot. 68: 636-648.

25. Van der Auwera GA, Timmery S, Hoton F, Mahillon J. 2007. Plasmid exchanges among members of the Bacillus cereus group in foodstuffs. Int. J. Food Microbiol. 113: 164-172.

26. Ullom JN, Frank M, Gard EE, Horn JM, Labov SE, Langry K, et al. 2001. Discrimination between bacterial spore types using time-of-flight mass spectrometry and matrix-free infrared laser desorption and ionization. Anal. Chem. 73: 2331-2337.

27. Aronson A. 2002. Sporulation and delta-endotoxin synthesis by Bacillus thuringiensis. Cell. Mol. Life Sci. 59: 417-425.

28. Drobniewski FA. 1993. Bacillus cereus and related species. Clin. Microbiol. Rev. 6: 324-338.

29. Emmerson AM, Hawkey PM, Gillespie SH. 1997. Bacillus, Aliscylobacillus and Paenibacillus, pp. 185-207. In Berkeley RCW, Logan NA, editors. Principles and Practice of Clinical Bacteriology. Chichester: John Wiley \& Sons.

30. Helgason E, Okstad OA, Caugant DA, Johansen HA, Fouet A, Mock M, et al. 2000. Bacillus anthracis, Bacillus cereus, and Bacillus thuringiensis-one species on the basis of genetic evidence. Appl. Environ. Microbiol. 66: 2627-2630.

31. Punina NV, Zotov VS, Parkhomenko AL, Parkhomenko TU, Topunov AF. 2013. Genetic diversity of Bacillus thuringiensis from different geoecological regions of Ukraine by analyzing the $16 \mathrm{~S}$ rRNA and gyrB genes and by AP-PCR and saAFLP. Acta Naturae 5: 90-100.

32. Murray PR. 2010. Matrix-assisted laser desorption ionization time-of-flight mass spectrometry: usefulness for taxonomy and epidemiology. Clin. Microbiol. Infect. 16: 1626-1630. 
33. Klevan A, Tourasse NJ, Stabell FB, Kolstø AB, Økstad OA. 2007. Exploring the evolution of the Bacillus cereus group repeat element bcr1 by comparative genome analysis of closely related strains. Microbiology 153(Pt 11): 3894-908.

34. Ash C, Farrow JA, Dorsch M, Stackebrandt E, Collins MD. 1991. Comparative analysis of Bacillus anthracis, Bacillus cereus, and related species on the basis of reverse transcriptase gene sequencing of $16 \mathrm{~S}$ rRNA. Int. J. Syst. Bacteriol. 41: 343346.

35. Alocilja EC and Radke SM. 2003. Market analysis of biosensors for food safety. Biosens Bioelectron. 18: 841-846.

36. Pal S, Alocilja EC and Downes FP. 2007. Nanowire labeled direct-charge transfer biosensor for detecting Bacillus species. Biosens. Bioelectron. 22: 2329-2336.

37. Halket G, Dinsdale AE, Logan NA. 2010. Evaluation of the VITEK2 BCL card for identification of Bacillus species and other aerobic endospore formers. Lett. Appl. Microbiol. 50: 120-126.

38. Weisburg WG, Barns SM, Pelletier DA, Lane DJ. 1991. 16S ribosomal DNA amplification for phylogenetic study. J. Bacteriol. 173: 697-703.

39. Frank JA, Reich CI, Sharma S, Weisbaum JS, Wilson BA, Olsen GJ. 2008. Critical evaluation of two primers commonly used for amplification of bacterial 16S rRNA genes. Appl. Environ. Microbiol. 74: 2461-2470.

40. http://www.ncbi.nlm.nih.gov/blast/bl2seq/wblast2.cgi

41. Borgonie G, Claeys M, Leyns F. 1996. Effect of nematicidal Bacillus thuringiensis strains on free-living nematodes. 2. Ultrastructural analysis of the intoxication process in using time-of-flight mass spectrometry and matrix-free infrared laser desorption and Caenorhabditis elegans. Fundam. Appl. Nematol. 19: 407-414.

42. Haigh J, Degun A, Eydmann M, Millar M, Wilks M. 2011. Improved performance of bacterium and yeast identification by a commercial matrix-assisted laser desorption ionizationtime of flight mass spectrometry system in the clinical microbiology laboratory. J. Clin. Microbiol. 49: 3441.

43. Schnepf E, Crickmore N, Van Rie J, Lereclus D, Baum J, Feitelson J, et al. 1998. Bacillus thuringiensis and its pesticidal crystal proteins. Microbiol. Mol. Biol. Rev. 62: 775-806.

44. Jeyaram K, Romi W, Singh TA, Adewumi GA, Basanti K, Oguntoyinbo FA. 2011. Distinct differentiation of closely related species of bacillus subtilis group with industrial importance. J. Microbiol. Methods. 87: 161-164.

45. Roh JY, Choi JY, Li MS, Jin BR, Je YH. 2007. Bacillus thuringiensis as a specific, safe, and effective tool for insect pest control. J. Microbiol. Biotechnol. 17: 547-559.

46. Chenau J, Fenaille F, Caro V, Haustant M, Diancourt L, Klee SR, et al. 2014. Identification and validation of specific markers of Bacillus anthracis spores by proteomics and genomics approaches. Mol. Cell Proteomics. 13: 716-732.

47. Lasch P, Beyer W, Nattermann H, Stämmler M, Siegbrecht E, Grunow R, et al. 2009. Identification of Bacillus anthracis by using matrix-assisted laser desorption ionization-time of flight mass spectrometry and artificial neural networks. Appl. Environ. Microbiol. 75: 7229-7242.

48. Lasch P, Wahab T, Weil S, Pályi B, Tomaso H, Zange S, et al. 2015. Identification of highly pathogenic microorganisms by matrix-assisted laser desorption ionization-time of flight mass spectrometry: results of an interlaboratory ring trial. J. Clin. Microbiol. 53: 2632-2640.

49. Ryzhov V, Hathout Y, Fenselau C. 2000. Rapid characterization of spores of Bacillus cereus group bacteria by matrix-assisted laser desorption-ionization time-of-flight mass spectrometry. Appl. Environ. Microbiol. 66: 3828-3834.

50. Wilson MK, Abergel RJ, Raymond KN, Arceneaux JE, Byers BR. 2006. Siderophores of Bacillus anthracis, Bacillus cereus, and Bacillus thuringiensis. Biochem. Biophys. Res. Commun. 348: 320-325.

51. Maughan H, Van der Auwera G. 2011. Bacillus taxonomy in the genomic era finds phenotypes to be essential though often misleading. Infect. Genet. Evol. 11: 789-797.

52. Fakruddin MD, Sarker N, Ahmed MM, Noor R. 2012. Protein profiling of Bacillus thuringiensis isolated from agroforest soil in Bangladesh. Aspac J. Mol. Biol Biotechnol. 20: 139-145.

53. Cho SH, Kang SH, Lee YE, Kim SJ, Yoo YB, Bak YS, et al. 2015. Distribution of toxin genes and enterotoxins in Bacillus thuringiensis isolated from microbial insecticide products. J. Microbiol. Biotechnol. 25: 2043-2048.

54. Modrie P, Beuls E, Mahillon J. 2010. Differential transfer dynamics of pAW63 plasmid among members of the Bacillus cereus group in food microcosms. J. Appl. Microbiol. 108: $888-897$. 